\title{
The Helsinki Face Transplantation : Surgical aspects and 1-year outcome
}

\section{Lassus, Patrik}

2018-02

Lassus , P , Lindford, A , Vuola , J , Bäck , L , Suominen , S , Mesimäki , K, Wilkman , T , Ylä-Kotola , T, Tukiainen , E , Kuokkanen, H\& Törnwall , J 2018 , ' The Helsinki Face Transplantation : Surgical aspects and 1-year outcome ' , Journal of Plastic, Reconstructive \& Aesthetic Surgery , vol. 71 , no. 2 , pp. 132-139 . https://doi.org/10.1016/j.bjps.2017.10.007

http://hdl.handle.net/10138/300882

https://doi.org/10.1016/j.bjps.2017.10.007

publishedVersion

Downloaded from Helda, University of Helsinki institutional repository.

This is an electronic reprint of the original article.

This reprint may differ from the original in pagination and typographic detail.

Please cite the original version. 


\title{
The Helsinki Face Transplantation: Surgical aspects and 1-year outcome
}

\author{
Patrik Lassus ${ }^{a, *}$, Andrew Lindford a, Jyrki Vuola ${ }^{a}$, Leif Bäck ${ }^{b}$, \\ Sinikka Suominen ${ }^{a}$, Karri Mesimäki ${ }^{c}$, Tommy Wilkman ${ }^{c}$, \\ Tuija Ylä-Kotola ${ }^{a}$, Erkki Tukiainen ${ }^{a}$, Hannu Kuokkanen ${ }^{a}$, \\ Jyrki Törnwall ${ }^{c}$
}

\author{
a Department of Plastic Surgery, Töölö Hospital, Helsinki University Hospital, University of Helsinki, Finland \\ ${ }^{b}$ Department of Otorhinolaryngology - Head \& Neck Surgery, Helsinki University Hospital, University of \\ Helsinki, Helsinki, Finland \\ c Oral and Maxillofacial Surgery, Helsinki University Hospital, University of Helsinki, Helsinki, Finland
}

Received 28 May 2017; accepted 4 October 2017

\author{
KEYWORDS \\ Face transplant; \\ Facial VCA; \\ Vascularized \\ composite \\ allotransplantation; \\ Facial \\ allotransplantation
}

\begin{abstract}
Summary Background: Since 2005, at least 38 facial transplantations have been performed worldwide. We herein describe the surgical technique and 1-year clinical outcome in Finland's first face transplant case.

Methods: A 34-year-old male who had a severe facial deformity following ballistic trauma in 1999 underwent facial transplantation at the Helsinki University Hospital on 8th February 2016. Three-dimensional (3D) technology was used to manufacture donor and recipient patientspecific osteotomy guides and a donor face mask. The facial transplant consisted of a Le Fort II maxilla, central mandible, lower $2 / 3$ of the midface muscles, facial and neck skin, oral mucosa, anterior tongue and floor of mouth muscles, facial nerve (three bilateral branches), and bilateral hypoglossal and buccal nerves.

Results: At 1-year follow-up, there have thus far been no clinical or histological signs of rejection. The patient has a good aesthetic outcome with symmetrical restoration of the mobile central part of the face, with recovery of pain and light touch sensation to almost the entire facial skin and intraoral mucosa. Electromyography at 1 year has confirmed symmetrical muscle activity in the floor of the mouth and facial musculature, and the patient is able to produce spontaneous smile. Successful social and psychological outcome has also been observed. Postoperative complications requiring intervention included early (nasopalatinal fistula, submandibular sialocele, temporomandibular joint pain and transient type 2 diabetes) and late (intraoral wound and fungal infection, renal impairment and hypertension) complications.
\end{abstract}

\footnotetext{
* Corresponding author. Department of Plastic Surgery, Töölö Hospital, Helsinki University Hospital, Topeliuksenkatu 5, P.0. Box 00029 HUS, Helsinki, Finland.

E-mail address: patrik.lassus@hus.fi (P. Lassus).
} 
Conclusion: At 1 year, we report an overall good functional outcome in Finland's first face transplant.

(c) 2017 British Association of Plastic, Reconstructive and Aesthetic Surgeons. Published by Elsevier Ltd. All rights reserved.

\section{Introduction}

The past 10 years have seen rapid development in the field of facial vascularised composite allotransplantation (VCA) with promising functional, aesthetic and psychological outcomes. ${ }^{1}$ Facial VCA is the only reconstructive option available that can successfully replace lost or severely damaged central facial units such as the oral commissure, maxilla, nose and eyelids as functional outcomes with conventional reconstructive techniques invariably fall short. To date, it is estimated that at least 38 facial transplantations (including Finland's first case) have been performed worldwide. However, only two-thirds of all face transplants have been published in the peer-reviewed literature with details on surgical technique and clinical outcomes. ${ }^{2-21}$ Furthermore, transparent description of all complications and revision surgery has been somewhat lacking in this still new but largely experimental field of reconstructive surgery. ${ }^{2}$ Thus far, even though the experience of centres worldwide performing facial transplantation has proved its surgical feasibility with good functional outcomes, only now are we beginning to see the long-term outcomes. $1,7,22$

We herein describe our experience in facial allotransplantation with details on the surgical procedure and clinical outcome at 12 months. In addition, a thorough review is provided of all complications encountered and revision surgical procedures performed to date.

\section{Methods: recipient and donor}

\section{Recipient}

\section{Evaluation pre-transplantation}

A 34-year-old male who had sustained a self-inflicted facial gunshot injury in 1999 was selected for facial transplantation (Figure 1). He had suffered loss of the midface soft tissues and nose, maxilla and central mandible and had complete bilateral blindness. He had previously undergone 28 surgical procedures including five microvascular reconstructions. However, the patient suffered from persistent, recurrent soft tissue and hardware infections. He had limited lip closure and tongue projection due to an absent tip and floor of the mouth scarring. There were consequent problems with eating and speech further exacerbated by limited mouth opening and unsatisfactory dentition as dental implants were not possible. In addition, the patient suffered from absent nasal breathing. Clinically, there was normal bilateral masseter function, and facial nerve innervation of orbicularis oculi was symmetrical and normal. Facial nerve innervation to orbicularis oris was symmetrical, but muscle function was severely inhibited by scarring. There was absent function of the zygomaticus muscles, but normal function of depressor anguli oris muscles. 3D CT scans of the facial skeleton revealed marked loss of facial height and central facial collapse (Figure 2). The patient was otherwise healthy, blood group 0 , rhesus positive, and immunologically had a panel reactive antibody status of $33 \%$. Serological status included cytomegalovirus and Epstein-Barr virus positivity. The patient underwent a 2-year psychological evaluation that involved three semi-structured interviews by a clinical psychologist. These included initial assessment of any psychiatric diagnoses or substance abuse, followed by evaluation of the patient's readiness for the operation, prediction of psychological reactions, possible risk factors and compliance with treatment after transplantation. The patient's ability to receive and process information was also assessed to evaluate his capability to give informed consent and ultimately was deemed to be suitable for facial VCA. Whilst the patient was strongly motivated for the treatment, he was also fully informed about all the risks, postoperative course and possible sequelae.
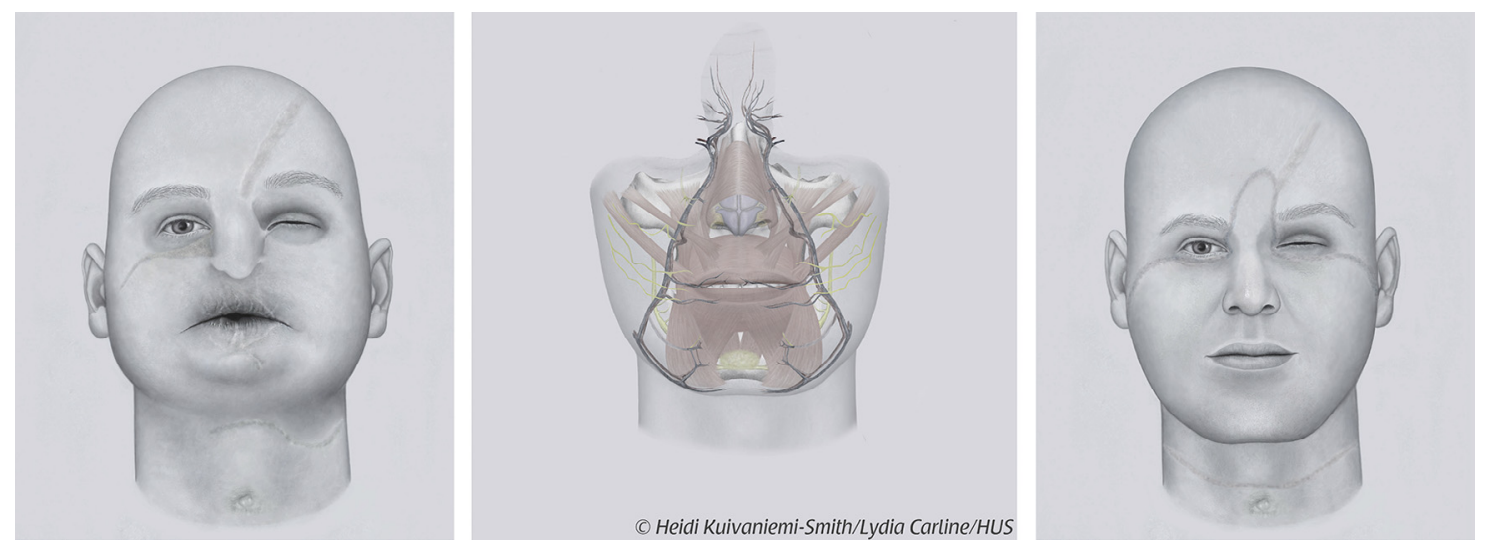

Figure 1 Illustration of patient preoperatively, donor facial allograft and post transplantation. 


\section{Preoperative}


\section{Postoperative}
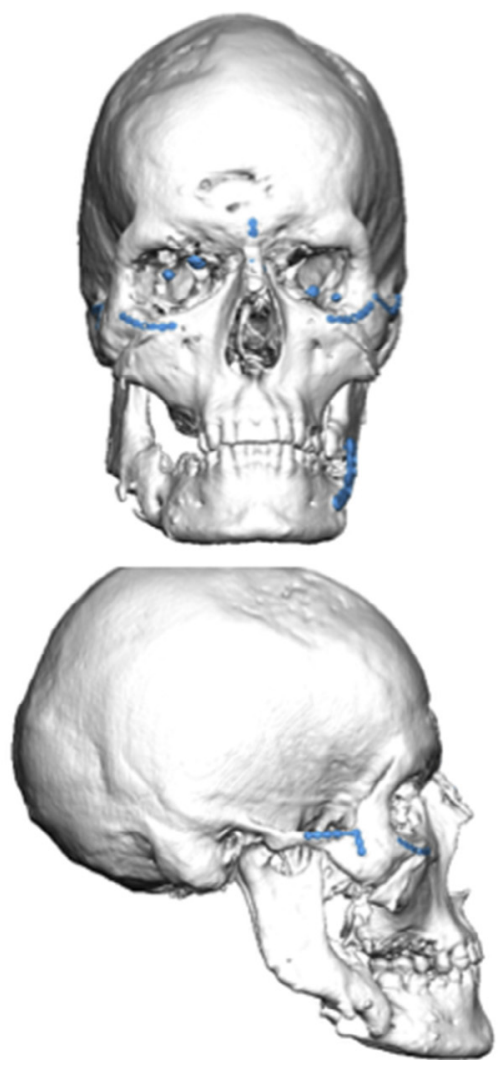

Figure 2 3D CT scan of skeletal anatomy revealing marked loss of facial height and central facial collapse, and 3D CT scan at 12 months postoperatively.

\section{D planning of osteotomy and cutting guides}

We used Planmeca ${ }^{\circledR}$ (Planmeca Oy, Helsinki, Finland), a Helsinki-based company who specialise in 3D imaging and CAD/CAM (computer-aided design and computer-aided manufacturing) software, to manufacture customised recipient osteotomy guides and generic guides for the donor. The generic donor osteotomy guides were produced according to the measurements derived from the patient's planned resection.

\section{Donor}

Consent for facial tissue donation was obtained only after consent for solid organ donation was obtained. The donor was selected on the basis of matching of gender, skin colour, suitable age, facial dimensions and dentition. The donor was blood group compatible, and the T- and B- cell cross match was negative. Because of the anonymity requirements for organ donors in Finland, no other detailed information can be disclosed about the donor.

On the day of transplantation, 3D CT angiogram scans were obtained from the donor and transferred to Planmeca ${ }^{\circledR}$ for virtual 3D planning of customised donor patient osteotomy guides. Virtual planning was complete within $3 \mathrm{~h}$, and osteotomy lines were fine-tuned so that the donor's maxilla and mandible would fit as well as possible. The customised osteotomy guides were printed during the time of facial procurement surgery, and the actual guides were produced and ready for use prior to the performing of the osteotomies. Digital photographs were also taken of the donor face for 3D modelling and printing of a donor facemask using a new process earlier described by our institution. ${ }^{23}$

\section{Facial allograft procurement}

A brain-dead, beating heart donation was planned to enable thorough haemostasis during procurement and limit bleeding after revascularisation. The donor was a multi-organ donor of the heart, lungs, liver, kidneys and pancreas. Following inspection of the internal abdominal organs, upper facial dissection commenced simultaneously with the abdominal organ transplant surgeons. All skin and soft tissues from the glabellar and infraorbital regions with incisions running along the subciliary margins of the lower eyelids and including the orbicularis oculi muscles were dissected. Maxillary osteotomy guides were fixed in place to the nasal radix, medial orbital margins and both zygomatic maxillary processes. The infraorbital nerves were identified in the inferior orbital fissure and labelled. Bilateral preauricular dissection of the facial nerve branches to the cheek and lips was performed at the anterior edge of the parotid glands. Dissection then continued anteriorly along the masseteric fascia, and within the buccal fat pad, the buccal nerves were identified and included in the facial allograft. The external carotid arteries and internal jugular veins were then dissected bilaterally, with preservation of the facial 
vessels and submandibular glands within the allograft. The hyoid bone and anterior floor of the mouth muscles were also included in the allograft along with intraoral cheek mucosa up to the anterior tonsillar pillars, ventral portion of the tongue and hypoglossal nerves. Bilateral ascending ramus mandibular sagittal split osteotomies were then performed with identification and inclusion of the inferior alveolar nerves. Le Fort II osteotomies (including the nose, nasal cartilage, septum and nasal bones) were performed using the customised cutting guides. The maxillary segment was then levered caudally with division of the nasal septum, and there was inclusion of about $1 \mathrm{~cm}$ of soft palate along with the hard palate. The facial allograft was then isolated on the vascular pedicles. Simultaneously, a right radial forearm flap was also harvested to act as a sentinel flap.

All organs were then perfused simultaneously with the facial tissues perfused through a cannula placed in the aortic arch with cold Wisconsin solution. Following removal of the heart and lungs, the facial allograft and sentinel flap were detached, further perfused on a back table and then subsequently transported in ice water slurry. Following procurement of the other abdominal organs, a cephalic vein graft and fascia lata grafts were also harvested, and finally, a 3D manufactured face mask was attached to the donor facial defect.

\section{Recipient debridement}

Simultaneous recipient patient debridement was commenced after tracheostomy. Definitive debridement commenced once the donor facial allograft was confirmed to be viable and perfused through the vascular pedicles. Le Fort II maxillary and central mandible segments were removed using customised osteotomy guides. Central facial skin and soft tissue including all poor quality tissue was removed along with the anterior floor of the mouth, ventral scarred tongue and a variable portion of poor quality soft palate tissue consisting of earlier free flap tissue. Recipient vessels were dissected in a very scarred neck (internal jugular vein branches bilaterally, external carotid artery on the left and facial artery on the right) along with bilateral hypoglossal nerves. Facial nerve branches were dissected to lie in proximity to the subsequent donor target muscles. Remnants of the orbicularis oris muscle with scar tissue attached to it was split in the midline and left in situ with its own neurovascular supply intact. In addition, remnants of the zygomatic muscles were spared for subsequent attachment. Infraorbital and inferior alveolar sensory nerves could not be identified because of extensive scarring.

\section{Facial tissue transplantation}

Before the restoration phase started, mandible sagittal osteotomies using 3D-printed custom-made donor osteotomy guides were performed on the side table. The donor facial maxilla and central mandible were first fixed into place. Arterial anastomoses were performed between external carotid arteries on the left and facial arteries on the right (with a vein graft). Venous anastomoses involved the donor allograft facial vein to a branch of the internal jugular vein on the right and two further venous anastomoses on the left. Three branches (zygomatic and buccal) of the facial nerve on both sides were anastomosed as distally as possible, and bilateral end-to-side hypoglossal nerve anastomoses were also carried out. The recipient's own divided medial ends of the orbicularis oris muscle were tunnelled subcutaneously within the donor allograft's upper and lower lip tissue and sutured about $2 \mathrm{~cm}$ medial to the contralateral commissures under appropriate tension. The remnants of the patient's partly functioning zygomatic muscles were attached to the equivalent muscular region in the allograft. Bilateral buccal sensory nerves were sutured end-to-end along with bilaterally both lip and cheek facial nerve branches. Excess skin in the neck and preauricular regions was preserved to allow for postoperative biopsies for monitoring of rejection and for postoperative swelling and avoidance of tension at the suture line. Simultaneously, transplantation of the sentinel (radial forearm) flap was performed to the right lateral thigh using the lateral femoral circumflex vessels as recipient vessels.

\section{Immunosuppression and infection control}

Induction immunosuppression involved rabbit antithymocyte globulin $(1.5 \mathrm{mg} / \mathrm{kg})$ for 4 days, and tacrolimus-based triple therapy (target 13-16 $\mathrm{ng} / \mathrm{ml}$ ) with mycophenolate mofetil and methylprednisolone (500 $\mathrm{mg}$ iv) with tapering doses. Maintenance immunosuppression entailed mycophenolate mofetil $(1 \mathrm{~g} \times 2)$, tacrolimus (with a goal of initial trough levels of 6-8 $\mathrm{ng} / \mathrm{ml}$ ) and prednisolone. Regular punch biopsies were obtained from the sentinel flap and facial allograft skin.

The antibiotic protocol included clindamycin and ciprofloxacin for 3 weeks, caspofungin for 5 weeks, ganciclovir $5 \mathrm{mg} / \mathrm{kg}$ for 3 months and trimethoprim/sulfamethoxazole for 12 months.

\section{Results}

\section{Surgical procedure}

The duration of facial allograft harvest was $6 \mathrm{~h}$ (total multiorgan harvesting duration was $10 \mathrm{~h}$ ). The duration of the recipient patient's debridement was $10 \mathrm{~h}$ and facial restoration $9 \mathrm{~h}$. Total cold ischaemia time was $3 \mathrm{~h} 15 \mathrm{~min}$. The total surgical time was thus $19 \mathrm{~h}$, and the entire procedure from notification of a potential donor to completion of surgery took a total of $32 \mathrm{~h}$. The recipient operative blood loss was $3350 \mathrm{ml}$, and 7 units of packed red blood cells were transfused along with 4 units $(4 \times 400 \mathrm{ml})$ of albumin. There were no intraoperative complications.

\section{Post-surgery}

The supplemental file describes the postoperative event timeline. The length of stay in the Intensive Care Unit was 9 days, and the patient was decannulated on day 20 . He resumed a full oral diet on day 25 and was discharged home after 57 days. Careful follow-up arrangements were made with close corporation with the social services. Regular frequent outpatient follow-up with various members of the surgical team was arranged at first twice weekly and then at twice-monthly intervals after 6 months.

\section{Clinical outcome at 12 months follow-up}

To date (15 months), there have been no signs of acute rejection with prednisolone tapered to a current dose of 

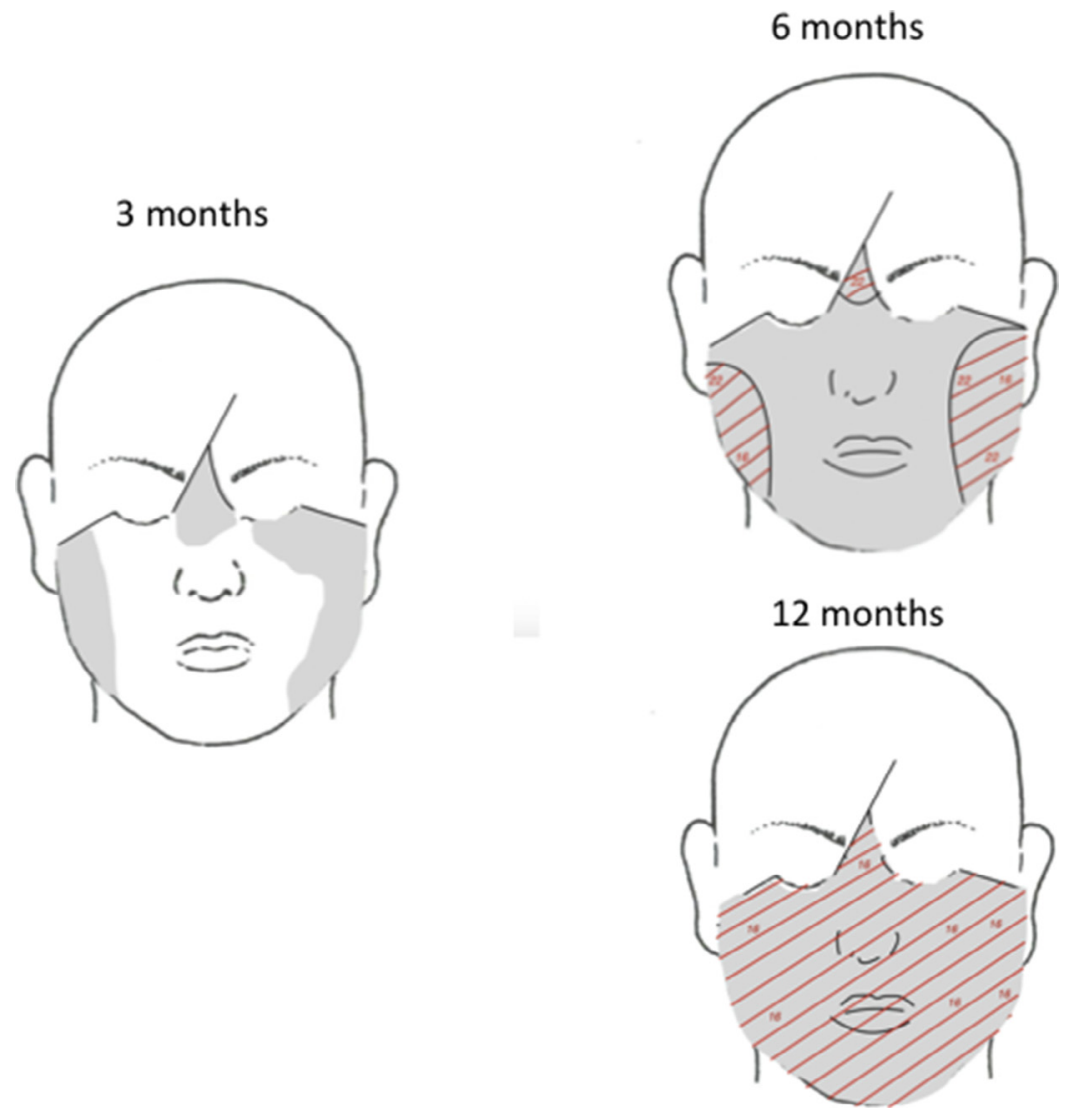

Figure 3 Sensation at 3, 6 and 12 months. Grey shading (light touch); red hash (sharp touch); 2-point discrimination when <22 mm.

$6 \mathrm{mg} /$ day. Tacrolimus trough levels are currently maintained at $6-8 \mathrm{ng} / \mathrm{ml}$. All facial allograft and sentinel flap biopsy results have so far been negative for rejection.

The patient reports an overall positive impact of the face transplant on his psychosocial well-being. Figure 1 shows the inset of the donor facial allograft. He had a successful aesthetic outcome with symmetrical restoration of the mobile central part of face. Pain and light touch sensation has been restored almost to the entire face and oral cavity, but discriminatory sensation of less than $16 \mathrm{~mm}$ is still lacking (Figure 3). Motor activity is present in all of the muscle groups, and this has been confirmed objectively by electomyographical (EMG) (Table 1. EMG results at 10 months). The patient also produces spontaneous smile. Mouth opening has now improved to greater than $31 \mathrm{~mm}$, and the patient is eating a normal diet. The patient has maintained the original good dental occlusion at 12 months, and there has not been any change in the position of the maxilla. There have been no signs of psychological disturbance postoperatively. For the assessment of the effect of facial VCA on the patient's quality of life (QOL), we applied the generic 15D health related $\mathrm{QOL}$ instrument ${ }^{24}$ and the European Organisation for Research and Treatment of Cancer QOL Questionnaire (EORTC QLQ-Head \& Neck 35 module). At 12 months follow-up, for 11 of the 15D instrument domains and for 33 of the 35 EORTC questions, the patient rated normal or near-normal function. In comparison to the preoperative status, improvement in speaking and breathing in the former and improvement in four domains (dry mouth, olfaction,
Table 1 EMG assessment of facial muscles at 10 months follow-up.

\begin{tabular}{lll}
\hline Muscle & Right & Left \\
\hline Lower orbicularis oculi & ++ & ++ \\
Nasalis & ++ & + \\
Orbicularis oris & ++ & ++ \\
Zygomaticus major & ++ & +++ \\
Genioglossus (XII) & + & ++ \\
\hline
\end{tabular}

XII Hypoglossal nerve; + severe impairment; ++ moderate impairment; +++ functional.

hoarseness and appearance) of the latter questionnaire was observed.

\section{Postoperative complications (Figure 4)}

\section{Surgical complications}

On postoperative day (POD) 7 , the patient had developed a nasopalatinal fistula because of partial separation of the allograft hard palate and patient's remaining soft palate, which required three surgical attempts until closure at POD 425. A salivary gland sialocele required ultrasound drainage of sterile saliva at POD 20. This occurred despite prophylactic intraoperative Botulinum toxin injections to donor submandibular glands to reduce salivary production. The patient suffered from temporary left temporomandibular joint (TMJ) 


\begin{tabular}{|l|l|}
\hline \multicolumn{2}{|c|}{ Post-operative complications } \\
\hline Early & Late \\
\hline - Nasopalatinal fistula & - Local Candida infection of \\
- Submandibular sialocele & $\begin{array}{l}\text { maxilla requiring } \\
\text { debridement and 3 dental } \\
\text { - Pain from dental } \\
\text { malocclusion }\end{array}$ \\
& - $\begin{array}{l}\text { Rentractions } \\
\text { - Hypertension }\end{array}$ \\
& - Transient type 2 diabetes \\
\hline
\end{tabular}

Figure 4 Postoperative complications.

pain and restricted mouth opening as a result of imperfect mandible position. At 6 weeks, a 3D CT scan revealed good dental occlusion, but the transplanted segment of mandible was slightly too wide with the right mandible turned outwards (Figure 2). An intraoral wound developed in the right upper gingiva at 5 months, and this led to a local Candida infection of the maxilla requiring debridement and three dental extractions.

\section{Immunosuppression related-complications}

There was a transient steroid-induced type 2 diabetes for 3 months. Mild to moderate renal impairment has been monitored since day 16 . Hypertension has been treated from postoperative week 5 .

\section{Discussion}

There have been at least 38 facial transplants performed to date involving varying amounts of facial soft tissue with or without a portion of the facial skeleton. Aesthetic and functional outcomes have thus far been encouraging. ${ }^{1-21,25} \mathrm{We}$ herein report our first case of facial transplantation in which the lower two-third of the face was transplanted en bloc with a Le Fort II maxilla and central mandible. At 12 months, our patient has a good aesthetic result with a symmetrical mobile part of the central face and motor activity in all muscle groups. The patient reports that the face transplant has had a positive impact on his psychological well-being and achieves an overall good score on the 15D QOL assessment. The financial cost of the transplant operation was 75,000 euros, and the overall cost for the first year following transplantation was 190,000 euros.

Patient selection for facial VCA requires careful multidisciplinary assessment, and it is noteworthy that our patient had complete bilateral blindness as a consequence of his original facial trauma. Although blindness has been considered by some to be a contraindication to facial VCA, a position paper by Carty et al concluded that the inclusion of blind patients in facial VCA programs should be advocated for on the basis of functional, social, rehabilitative and ethical grounds. ${ }^{26}$ Certainly for our patient, the emphasis was the restoration of function as a key indication for facial VCA, and we have not observed any negative outcomes related to the patient's blindness.

In severe self-inflicted ballistic trauma, conventional reconstructive procedures often fail to restore the essential facial functions (eating, breathing and speech). Earlier reports have confirmed the feasibility and promising functional and psychosocial outcomes after facial VCA after ballistic trauma. ${ }^{13,15,17,27,28}$ However, Kiwanuka et al report in 2 patients with self-inflicted ballistic trauma only incomplete sensory restoration and restricted masticatory movements at 1 year follow-up. Additionally, in only 1 patient, clear functional and psychosocial improvements were observed. The authors concluded that this could be partly attributed to the increased incidence in rejections and infections in the patient with a worse outcome. ${ }^{28}$ Our patient, also a victim of a selfinflicted ballistic trauma, clearly demonstrated an improvement in psychosocial and physical functional outcomes at 1 year. Although our patient also had early restriction of mandibular movements due to TMJ pain that required diet modification, over time, his mandibular movements improved, and the patient could resume a normal diet by 3-4 months post transplant. With regard to patients with a history of psychiatric illness and self-harm, the importance of thorough psychiatric screening prior to selection for facial VCA must be stressed, and it must be ensured that an adequate social support network is in place following surgery.

With regard to sensory reintegration, because of severe scarring of the recipient patient, only the buccal sensory nerves were available for anastomosis. However, improving pain and light touch sensation to the entire facial allograft has developed already at 12 months. We have observed that sensation developed initially from the periphery of the allograft for both pain and light touch. Siemionow $M$ et al have also corroborated this finding, and demonstrated that recovery of close to normal sensation can be expected following facial transplantation with or without repair of the sensory nerves. ${ }^{29}$ Hence, an interesting question could be posed, whether or not sensory nerves should be dissected at all to save valuable time.

The importance of preserving the patient's own functional units is an important issue that we considered carefully in our case. Despite a normally innervated orbicularis oris muscle, his lip function was very poor owing to severe scarring. Therefore, we preserved his orbicularis muscle and tunnelled this into the facial allograft's upper and lower lip tissue and attached the patient's partly functioning zygomatic muscles to the equivalent muscular region in the allograft. In the early postoperative period, he was noted to have good resting tone to the lip and zygomatic musculature. At 10 months EMG assessment, reasonable to good function was observed in the transplanted muscle groups. Furthermore, facelift procedures have not been necessary, and only the excision of excess skin has been performed. The Boston group recently reviewed their own and other centres' functional outcomes, and they observed that improvement in facial expression has been reported in $76 \%$ of all facial VCAs. ${ }^{25}$ Prior to transplantation, the patient had severe restriction in his tongue movement due to extensive scarring in the floor of the mouth. He had anterior tongue and floor of the mouth muscles transplanted with side-toend anastomosis of the hypoglossus nerve. Tongue movements were already seen by 3 months postoperatively, and at 12 months, the patient could move his tongue $3 \mathrm{~cm}$. We conclude that the transplantation of the anterior tongue is effective and can have remarkable functional benefit for the patient. 
The most serious complication we have encountered has been the presence of a palatal fistula that has caused problems with speech in particular. The cause of the palatal fistula was probably two-fold: reduced vascularity of the posterior part of the transplanted maxilla and because of the severe loss of facial height, the recipient and donor soft palates were at different levels leading to tension at the palatal repair.

With regard to immunology, we have so far not seen any acute rejection episodes with close, regular follow-up. Histopathological analyses of biopsies taken from the facial allograft and sentinel flap have been negative for rejection, and we have been able to reduce the steroid dose to $6 \mathrm{mg} /$ day and maintain a tacrolimus trough level of $6-8 \mathrm{ng} / \mathrm{ml}$. A previous study by Kueckelhaus et al has demonstrated the usefulness of the sentinel flap in rejection monitoring by providing a reliable correlation between biopsies taken from the facial allograft and sentinel flaps. ${ }^{30}$ In our patient, immunosuppression has resulted in chronic renal impairment, hypertension and a transient type 2 diabetes. In the recent review by Lantieri et al, at long-term follow-up of 7 patients, 3 had hypertension, with 1 requiring therapy, and all patients had a reduction in the glomerular filtration rate. ${ }^{7} \mathrm{~A}$ recent report by Kanitakis et $\mathrm{al}^{22}$ has described the possibility of chronic rejection in human VCAs, but its pathogenesis, diagnosis and treatment remain unresolved.

Aycart et al recently reviewed all published QOL outcomes after facial VCA performed worldwide. ${ }^{31}$ They noted that QOL outcomes have been reported in only 14 facial VCA recipient cases and that the instruments used have varied widely. Overall, however, they concluded that there seems to be an improvement in the QOL following facial VCA. We applied the validated 15D health related QOL instrument ${ }^{24}$ that assesses 15 different dimensions. Its use in head and neck cancer patients has been previously reported by our institution. ${ }^{32}$ We observed a clear improvement in several of the 15D and EORTC QOL domains when comparing pre- and postoperative scores.

\section{Conclusions}

Finally, we can report that our experience is in alignment with that of other facial VCA centres, in that facial transplantation is technically feasible with the possibility of good functional outcomes with the caveat that revision surgery is likely to be necessary. A recent update by Sosin $M$ and Rodriguez ED ${ }^{2}$ concluded that there is an essential need for the timely reporting of all cases of facial VCA with complete complication and outcome profiles. With this in mind, we hope that our experience will provide a useful addition to the medical literature.

\section{Conflict of interest}

None declared.

\section{Acknowledgements}

Guy’s, Kings' \& St. Thomas Medical School Anatomy department, London.
Heidi Kuivaniemi-Smith and Lydia Carline for kindly providing the illustration for Figure 1 and Annastiina Husso, MD, for Figure 3.

\section{Appendix A. Supplementary data}

Supplementary data related to this article can be found at https: // doi.org/10.1016/j.bjps.2017.10.007.

\section{References}

1. Khalifian S, Brazio PS, Mohan R, et al. Facial transplantation: the first 9 years. Lancet 2014 Dec 13;384(9960):2153-63.

2. Sosin M, Rodriguez ED. The face transplantation update: 2016. Plast Reconstr Surg 2016 Jun;137(6):1841-50.

3. Devauchelle B, Badet L, Lengelé $B$, et al. First human face allograft: early report. Lancet 2006 Jul 15;368(9531):203-9.

4. Guo S, Han Y, Zhang X, et al. Human facial allotransplantation: a 2-year follow-up study. Lancet 2008 Aug 23;372(9639):6318.

5. Siemionow M, Papay F, Alam D, et al. Near-total human face transplantation for a severely disfigured patient in the USA. Lancet 2009 Jul 18;374(9685):203-9.

6. Lantieri L, Hivelin M, Audard V, et al. Feasibility, reproducibility, risks and benefits of face transplantation: a prospective study of outcomes. Am J Transplant 2011 Feb;11(2):36778.

7. Lantieri L, Grimbert P, Ortonne N, et al. Face transplant: longterm follow-up and results of a prospective open study. Lancet 2016 Oct 1;388(10052):1398-407.

8. Pomahac B, Pribaz J, Eriksson E, et al. Restoration of facial form and function after severe disfigurement from burn injury by a composite facial allograft. Am J Transplant $2011 \mathrm{Feb}$;1 (2): 386-93.

9. Pomahac B, Pribaz J, Eriksson E, et al. Three patients with full facial transplantation. N Engl J Med 2012 Feb 23;366(8):71522.

10. Cavadas PC, Ibáñez J, Thione A. Surgical aspects of a lower face, mandible, and tongue allotransplantation. J Reconstr Microsurg 2012 Jan;28(1):43-7.

11. Petruzzo P, Kanitakis J, Testelin S, et al. Clinicopathological findings of chronic rejection in a face grafted patient. Transplantation 2015 Dec;99(12):2644-50.

12. Sicilia-Castro D, Gomez-Cia T, Infante-Cossio P, et al. Reconstruction of a severe facial defect by allotransplantation in neurofibromatosis type 1: a case report. Transplant Proc 2011 Sep;43(7):2831-7.

13. Barret JP, Gavaldà J, Bueno J, et al. Full face transplant: the first case report. Ann Surg 2011 Aug;254(2):252-6.

14. Lantieri L. Face transplant: a paradigm change in facial reconstruction. J Craniofac Surg 2012 Jan;23(1):250-3.

15. Roche NA, Vermeersch HF, Stillaert FB, et al. Complex facial reconstruction by vascularized composite allotransplantation: the first Belgian case. J Plast Reconstr Aesthet Surg 2015 Mar; 68(3):362-71.

16. Özel AȘ, Güçlü ZA, Gülșen A, Özmen S. The importance of the condition of the donor teeth and jaws during allogeneic face transplantation. J Craniofac Surg 2015 Jun;26(4):133841.

17. Dorafshar AH, Bojovic B, Christy MR, et al. Total face, double jaw, and tongue transplantation: an evolutionary concept. Plast Reconstr Surg 2013 Feb;131(2):241-51.

18. Chandraker A, Arscott R, Murphy GF, et al. The management of antibody-mediated rejection in the first presensitized recipient of a full-face allotransplant. Am J Transplant 2014 Jun;14(6): 1446-52. 
19. Maciejewski A, Krakowczyk $Ł$, Szymczyk C, et al. The first immediate face transplant in the world. Ann Surg 2016 Mar;263(3): e36-9.

20. Westvik TS, Dermietzel A, Pomahac B. Facial restoration by transplantation: the Brigham and Women's face transplant experience. Ann Plast Surg 2015 May;74(Suppl 1):S2-8.

21. Sosin M, Ceradini DJ, Levine JP, et al. Total face, eyelids, ears, scalp, and skeletal subunit transplant: a reconstructive solution for the full face and total scalp burn. Plast Reconstr Surg 2016 Jul;138(1):205-19.

22. Kanitakis J, Petruzzo P, Badet L, et al. Chronic rejection in human vascularized composite allotransplantation (hand and face recipients): an update. Transplantation 2016 Oct;100(10): 2053-61.

23. Mäkitie AA, Salmi M, Lindford A, Tuomi J, Lassus P. Threedimensional printing for restoration of the donor face: a new digital technique tested and used in the first facial allotransplantation patient in Finland. J Plast Reconstr Aesthet Surg 2016 Oct 5.

24. Sintonen $\mathrm{H}$. The $15 \mathrm{D}$ instrument of health-related quality of life: properties and applications. Ann Med $2001 \mathrm{Jul} ; 33$ (5):328-36.

25. Fischer S, Kueckelhaus M, Pauzenberger R, Bueno EM, Pomahac B. Functional outcomes of face transplantation. Am J Transplant 2015 Jan;15(1):220-33.
26. Carty MJ, Bueno EM, Lehmann LS, Pomahac B. A position paper in support of face transplantation in the blind. Plast Reconstr Surg 2012 Aug;130(2):319-24.

27. Meningaud JP, Hivelin M, Benjoar MD, Toure G, Hermeziu O, Lantieri L. The procurement of allotransplants for ballistic trauma: a preclinical study and a report of two clinical cases. Plast Reconstr Surg 2011 May;127(5):1892-900.

28. Kiwanuka H, Aycart MA, Gitlin DF, et al. The role of face transplantation in the self-inflicted gunshot wound. J Plast Reconstr Aesthet Surg 2016 Dec;69(12):1636-47.

29. Siemionow M, Gharb BB, Rampazzo A. Pathways of sensory recovery after face transplantation. Plast Reconstr Surg 2011 May; 127(5):1875-89.

30. Kueckelhaus M, Fischer S, Lian CG, et al. Utility of sentinel flaps in assessing facial allograft rejection. Plast Reconstr Surg 2015 Jan;135(1):250-8.

31. Aycart MA, Kiwanuka H, Krezdorn N, et al. Quality of life after face transplantation: outcomes, assessment tools, and future directions. Plast Reconstr Surg 2017 Jan;139(1):194203.

32. Aro K, Bäck L, Loimu V, et al. Trends in the 15D health-related quality of life over the first year following diagnosis of head and neck cancer. Eur Arch Otorhinolaryngol 2016 Aug;273(8):214150. 